\title{
Research Progress of Soil Water Infiltration
}

\author{
Xia Qing ${ }^{1}$, Han Haojie ${ }^{1}$, Xiong Jinran ${ }^{1}$, Zheng Caixia*1, Zhang Zhiliang ${ }^{1}$, Huang Huiqiang ${ }^{1}$, Zhao qin ${ }^{1}$ \\ ${ }^{1}$ College of Water Conservancy and Hydropower Engineering, Sichuan Agricultural University, 625014, Ya'an, Sichuan, China
}

\begin{abstract}
Soil water is an important link in the transformation of the "five waters", which determines the growth and production of crops. Mastering the scientific infiltration law is a key link to promote agricultural development. Based on the existing research results, this paper systematically summarizes the basic theories, test methods, influencing factors, simulation equations, prediction models and other results of soil water infiltration research at home and abroad so far, and discusses the future research development direction.
\end{abstract}

\section{Introduction}

Soil water refers to the water in the soil layer below the ground surface and above the groundwater surface (phreatic surface), also known as soil water in the unsaturated zone [1]. The movement of soil water is considered to be the most important part of the hydrological cycle and an important link in the transformation of the "five waters" (precipitation, plant water, surface water, soil water and groundwater). It plays a key role in the material circulation in the process of ecological development [2]. The process of soil infiltration is the link that connects surface water, groundwater and the bio-earth cycle, and affects the replenishment of soil water and the effective degree of soil moisture storage. As the only type of water that can be absorbed and used by plants and an important part of the field soil water cycle, soil water determines the growth and production of crops [3-7]. In the ecosystem, it maintains a dynamic energy balance and Material transmission [8]. All these fully illustrate the importance of soil water in the earth's ecological environment, and also reflect the necessity of soil water infiltration research[9].

Based on the existing research results, this paper systematically summarizes the basic theories, test methods, influencing factors, simulation equations, and prediction models of soil water infiltration research at home and abroad so far. This article analyzes the existing research results and their remaining shortcomings, discusses future research development directions, and provides references for further research on the process of soil moisture infiltration, in the hope that the continuously developing infiltration theory can be better applied in production practice and promote social development.

\section{2 theory of soil water infiltration}

The development of the basic theory of soil water infiltration has experienced the infiltration from one-dimensional vertical infiltration to multi-dimensional infiltration, from indoor artificial environment to outdoor natural test environment, from single variable to multiple variables, from saturated infiltration theory to unsaturated infiltration theory, from the equation model of infiltration process to the prediction model of infiltration parameters, from discipline branch to independent discipline, it has been more than 100 years since its development [10].

In the middle of the eighteenth Century, based on the importance and practical significance of infiltration process, relevant scholars in western countries carried out a series of theoretical studies on soil water infiltration and put forward many important results. In 1856, French engineer H.P.G. Darcy obtained the equation describing the relationship between the seepage velocity of water in saturated soil and the seepage slope through experiments, and this equation is also called the Darcy's law [11].In 1877, Brigs L. J observed the existence of surface tension in the experiment as the main reason for the retention of soil moisture, and then put forward the capillary hypothesis. The development of the theory of soil moisture infiltration began to transition to the micro field [12]. In 1907, Buckingham put forward the capillary potential theory. In 1920, the relationship between soil water potential and water content was obtained by Gardner study, so that the viewpoint of energy began to intervene in the research process of soil water infiltration [13].In 1931, Richards used mathematical methods for the first time in the research and calculation of unsaturated soil water infiltration. The theoretical study of soil infiltration began to develop from the direction of saturated one-dimensional infiltration to unsaturated multi-dimensional infiltration, and in the direction of

Author: xiaqing1999@126.com ,*Corresponding author: ciaxia818@163.com 
quantitative and dynamic research [14].In 1957, Philip successfully used the thermodynamic function to express the movement and distribution of soil moisture in the research process. This form has been widely applied [15]. In 1966, Philip proposed a more complete concept of the SPAC system. Through the unified energy index of water potential, he pointed out that the water in the system always moves from a higher water potential to a lower water potential. The study described the energy transfer process between various elements in the system from a quantitative perspective, and pushed the research and development of soil infiltration theory to a new stage [16]. In the 1950s and 1960s, China's theoretical research on soil moisture infiltration began, and it mainly used the morphological research viewpoints and methods of Soviet scholars to carry out applied research [17-18]. In 1988, Lei Zhidong et al. [19] published Soil Dynamics and proposed a solution to the spatial heterogeneity of soil water dynamic changes. In 1996, Zhang Weizhen et al. discussed and summarized the dynamic relationship and analysis methods between groundwater and soil water, and published Groundwater and Soil Hydrodynamics. In 1997, the first national soil physics academic seminar was held, at which the energetics research viewpoints in the process of soil infiltration were summarized and promoted. Since then, Chinese scholars have carried out in-depth research on the measurement and calculation methods of soil water infiltration SPAC system water and heat flux [10].

\section{3 soil moisture infiltration test method}

The research of soil moisture infiltration has been developed so far, and many soil infiltration measurement methods have been produced in experiments. In the early stage, it can be divided into field test and indoor measurement, including water injection method, double loop method, single loop method, artificial rainfall method, hydrology method and time domain reflectometer (TDR) method [20-21]. Due to the different principles and operating methods of different infiltration methods, the measurement results and their accuracy are often different.

\section{1 irrigation method}

The water injection method is the most classic method. This method calculates the infiltration rate by recording the amount of infiltration within a certain period of time. The test usually uses double-ring, constant-head equipment, and keeps the inner and outer rings of the infiltration equipment at the same water depth. This method saves time, effort and water, and is widely used in field flat ground experiments. However, it is limited to single-point test, and it is difficult to simulate the infiltration process and law under different slopes and rainfall intensity [22-23].

The basic principle of the Time Domain Reflectometer (TDR) method is to use probes to measure the time when electromagnetic waves encounter obstacles in the soil, to obtain the dynamic changes of soil moisture content, and then to estimate the soil moisture content. This method can monitor the change of infiltration rate at a fixed point for a long time, and the determination speed is fast and the accuracy is high [24].

Hood infiltration meter is a new type of tension infiltration meter. It conducts water through the water pipe, automatically collects and records the saturated hydraulic conductivity and infiltration rate of the soil, and the readings are relatively accurate and closer to the actual value [25]. Afterwards, the output data can be graphed through the software, and the measurement results are intuitive and clear. However, it still has shortcomings such as small infiltration area and lateral infiltration of instruments, and it cannot describe the dynamic infiltration process of soil water [26]. It needs to be improved in the future.

The Guelph infiltration meter can measure the soil infiltration rate, and its basic principle is similar to that of a Markov flask (constant head). Using the Guelph infiltration meter to conduct indoor tests can obtain infiltration parameters such as soil infiltration amount and wet front, and can observe the dynamic change process of parameters. It is easier to control the test process and can fully express the soil infiltration performance [27].

The disc infiltration meter method is a new method to determine the hydraulic parameters of soil infiltration. It is simple to operate, short in measurement period, and consumes less water for testing. The effect is better than the double loop infiltration meter method. Within a certain range, this method can be used to determine the hydraulic parameters of soil infiltration at any depth above the groundwater level. In addition, the disc infiltration meter can eliminate the influence of soil cracks, earthworm boreholes, plant root holes and other pores on the measurement [28]. This method has been widely used in soil water research and experimentation.

\section{2 hydrology law}

Hydrological method refers to the method of comparing and analyzing the actually measured rainfall or runoff test field data in a small watershed, and then using mathematical statistical analysis methods in hydrology to derive the soil infiltration equation, and then obtain the average soil moisture infiltration rate. The measurement results obtained in this way are more accurate, but the data collection process is more difficult, and the dynamic process of soil moisture infiltration cannot be obtained. It is suitable for use when measuring the infiltration rate in a large range [29-30].

\section{3 artificial rainfall method}

Compared with other methods, the artificial rainfall method can better simulate the situation of natural rainfall, and the water balance method can be used to estimate the amount of soil moisture infiltration. Its advantage is that it is less constrained by terrain such as slope and height, and can control the measurement time, precipitation intensity and other factors. However, it is 
not suitable for operation in the field, and has the disadvantages of high cost, large size, labor and time-consuming [31].

\section{4 dynamic monitoring platform for soil moisture infiltration}

After the 1990s, with the continuous development and progress of computer science and "3S" technology, countries began to build large-scale long-term soil moisture infiltration dynamic monitoring platforms, and gradually realized large-scale long-span monitoring. However, this technology still has limitations such as low spatial resolution and complicated relationship between acquisition parameters and soil moisture [32].

\section{4 factors affecting soil water infiltration}

According to the existing research results, the main factors affecting soil infiltration can be summarized into two points. On the one hand, soil water infiltration characteristics are mainly determined by the influence of soil bulk density, soil initial water content, soil texture, soil type, soil structure and soil organic matter and other physical and chemical properties of the soil; on the other hand, vegetation coverage, precipitation and Human interference and other factors outside the soil will also have a significant impact on the process of soil moisture infiltration [10].

\section{1 effects of soil physical and chemical properties}

\subsection{1 soil bulk density.}

Soil bulk density is the ratio of the weight of a certain volume of soil after drying to the same volume of water weight, and soil infiltration capacity is greatly affected by soil bulk density [33]. Many related studies have found that the soil infiltration rate, cumulative infiltration amount, and distance of soil wet front movement all decrease with the increase of soil bulk density. And the influence of soil bulk density on the infiltration rate gradually weakens with the increase of time [34-36]. Research by Li Zhuo et al. [37] showed that the relationship between soil bulk density and the number of macropores and the cumulative infiltration volume at 120 min is very similar, which shows that the influence of soil bulk density on infiltration characteristics is essentially realized by changing the number of macropores.

\subsection{2 soil texture.}

Soil texture is the combination of soil particles of different diameters in the soil. It is mainly divided into sandy soil, clay, loam, silt and other types according to the composition of soil particles, which has a significant impact on the soil infiltration process. The soil texture changes from light to heavier, the soil infiltration rate decreases, and the infiltration capacity decreases accordingly [38]. There is also a significant correlation between soil texture and infiltration capacity. Soils with tight structures have stronger infiltration capacity than other loosely structured soils. After the loose soil is compacted, its infiltration rate will be reduced to $2 \%$ of that before the loose soil compaction [39].

\subsection{3 soil contains organic matter .}

Soil organic matter generally refers to life-derived substances in the soil, including soil microorganisms, soil animals and their secretions, and plant residues and plant secretions in the soil [40]. Compared with soils lacking organic matter, soils rich in organic matter have changes in soil porosity and adsorption of soil particles, which will have a certain impact on the soil infiltration process. Shan Xiuzhi et al. [41] found that different organic matter content in soil has different influence processes on soil properties. When the organic matter content is in the range of less than $15.0 \mathrm{~g} / \mathrm{kg}$, under certain other conditions, if the organic matter content increases, the soil saturated hydraulic conductivity will increase. When the organic matter content is greater than $15.0 \mathrm{~g} / \mathrm{kg}$, under certain other conditions, if the organic matter content increases, the saturated hydraulic conductivity of the soil will decrease instead. Zheng Jian [42] studied the effect of biochar on soil organic matter and nitrogen content and found that adding biochar to the same bulk density soil can accelerate the infiltration rate. Within a certain range, as the mixing thickness and mixing amount of biochar increase, the infiltration rate also increases.

\subsubsection{Initial water content of}

Soil water content is the amount of water contained in the soil, which directly affects the initial infiltration rate of soil surface water [43]. With the increase of soil water content, the water absorption of soil particles will cause volume expansion (if the soil particle colloid content is large, this phenomenon will be more obvious), which will reduce soil pores and reduce water absorption, which affects soil water intake. Infiltration process [44]. Jia Zhijun [45] and Zhang Zhiguo [46] obtained the relationship between slope soil infiltration property parameters and soil water content through measured data in experiments, and the results showed that the two are linearly negatively correlated. The higher the initial soil moisture content, the shorter the time for the soil to reach a stable infiltration rate and the lower the infiltration rate. $\mathrm{Li} \mathrm{Fa}$ wen [47] showed that under certain other conditions, as the initial soil moisture content increases, the cumulative infiltration volume decreases.

\subsection{5 surface crust.}

Surface crusting refers to the phenomenon that some fine particulate matter fills the pores of the soil surface due to the impact of raindrops and surface runoff during the rainfall process, which leads to the phenomenon that the surface texture of the soil tends to be dense and the bulk 
density increases [39]. Too dense soil crust will reduce or even completely disappear the soil moisture infiltration channels, which will greatly weaken the soil infiltration capacity. Jia Zhijun et al. [48] found that the soil water content and infiltration capacity of the $0-50 \mathrm{~cm}$ loess plough layer were significantly affected by the surface crust. After removing soil crusts, it improves soil properties, increases soil water retention capacity, enhances infiltration capacity, and reduces water evaporation.

\section{2 influence of external environmental factors}

\subsection{1 vegetation coverage.}

The vegetation coverage rate reaches a certain level, and it can directly affect the local hydrological and ecological environment by reducing the evapotranspiration of precipitation, redistributing soil precipitation, reducing rainwater into the surface runoff and other methods [49]. According to the research results of Zhang Zhi qiang et al. [50], the succession of different types of vegetation in the subalpine dark coniferous forest area in the upper reaches of the Yangtze River will affect the saturated hydraulic conductivity of the soil. Wang Genxu[51] studies on alpine meadow vegetation also showed that vegetation has a significant impact on soil infiltration. Wang Bang tuan [52] and others have shown that vegetation coverage affects the infiltration process, and vegetation development will accelerate rainwater infiltration. Bai Sheng yuan [53] used loess soil pillars to study the effect of vegetation coverage on infiltration depth and found that different coverage methods and coverage have different effects on enhancing soil infiltration capacity.

\subsection{2 precipitation}

Table 1 Simulation equation of soil water infiltration process $[10]$

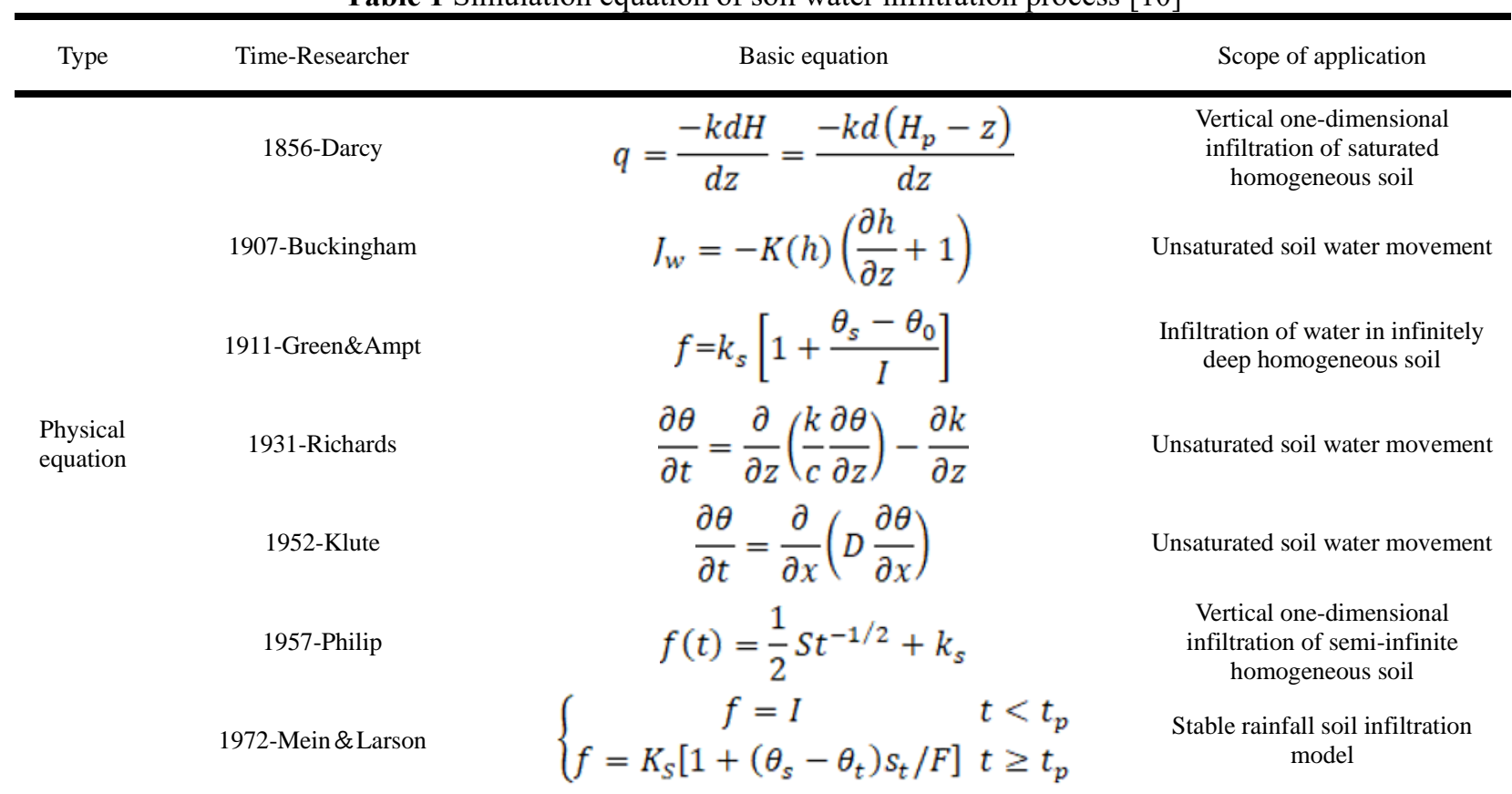

At present, the influence of rainfall intensity on the process of soil water infiltration has not yet formed a unified conclusion. Zhao Xi ning[54] and Shi Sheng xin[55] believed that during the precipitation process, the surface of the soil was directly impacted by water droplets, and the natural texture of the surface soil was disturbed, causing part of the originally static capillary pore water to be destroyed and released into the water flow. And the study found that the steady infiltration rate of soil increases with the increase of precipitation intensity. Yang Yonghui [56], Helalia A M [57], etc. believe that small particles carried by raindrops or runoff produced by rainfall can easily block the pores of the surface soil, resulting in skinning and other phenomena. With the increase of precipitation intensity, the greater the impact on the surface soil, the less stable soil infiltration rate. The physical and chemical properties and surface characteristics of the soil will affect the process of soil water infiltration during precipitation, so different conclusions may be drawn for different soil types and external conditions. In the existing related experimental studies, artificial rainfall is mostly used with constant rainfall intensity. However, the influence of precipitation in the actual environment on the process of soil water infiltration is very complicated and has many factors.

\section{5 simulation model of soil water infiltration process}

With the continuous development of soil infiltration theory and experience, scholars have begun to study the simulation model of soil water infiltration to describe the infiltration process of soil water. The following is a widely used soil water infiltration simulation model in practice and experiment. 


\begin{tabular}{|c|c|c|c|}
\hline & 1978-Chu & $\left\{\begin{array}{c}f=I \\
f=k(1+A / F)\end{array}\right.$ & $\begin{array}{l}\text { Infiltration calculation during } \\
\text { unsteady rainfall }\end{array}$ \\
\hline \multirow{6}{*}{$\begin{array}{l}\text { Empirical } \\
\text { formula }\end{array}$} & 1932-Kostiakov & $f(t)=a t^{-b}$ & $\begin{array}{l}\text { Vertical one-dimensional } \\
\text { infiltration }\end{array}$ \\
\hline & 1939-Horton & $f(t)=f_{c}+\left(f_{0}-f_{c}\right) e^{-a t}$ & $\begin{array}{l}\text { Unsaturated soil vertical } \\
\text { one-dimensional infiltration }\end{array}$ \\
\hline & 1958-Fang Zhengsan & $k_{t}=k+\frac{k_{1}}{t^{\alpha}}$ & $\begin{array}{l}\text { Vertical one-dimensional } \\
\text { infiltration }\end{array}$ \\
\hline & 1961-Holtan & $f=f_{c}+a(w-f)^{n}$ & Basin-scale rainfall infiltration \\
\hline & 1972-Smith & $\left\{\begin{array}{cc}i=R & t \leq t_{p} \\
i=i_{\infty}+A\left(t-t_{0}\right)^{-\alpha} & t>t_{p}\end{array}\right.$ & $\begin{array}{l}\text { Rainfall water infiltration in } \\
\text { different soils }\end{array}$ \\
\hline & 1986-Jiang Ding sheng & $f=f_{c}+\frac{\left(f_{1}-f_{c}\right)}{t^{\alpha}}$ & $\begin{array}{l}\text { Water infiltration in the Loess } \\
\text { Plateau }\end{array}$ \\
\hline
\end{tabular}

\section{6 prediction model of soil water infiltration parameters}

Due to the complexity of water movement in the unsaturated zone in the soil and the temporal and spatial variability of natural soil, so it is very difficult to obtain scientific and accurate soil water infiltration parameters through field tests [58]. The soil transfer function method is a method for predicting and obtaining soil water infiltration parameters that are difficult to obtain accurately through basic soil data that is available or relatively easy to obtain [9]. Regarding the method of establishing soil transfer function, the current applications include linear regression analysis model, nonlinear regression analysis model and artificial neural network model.

\section{1 linear regression prediction model for soil water infiltration parameters}

In 1979, Gupta and Larson [59] established a multiple linear regression fitting model for the first time, using basic physical and chemical parameters of soil including texture, organic matter, and density as input parameters to predict soil moisture characteristics and meet the accuracy requirements. In 1999, Minasny et al. [60] established a linear prediction model, using soil texture and density as input factors to predict soil moisture content. At the same time, it is observed that the accuracy of the parameters of the multiple linear regression prediction model is low, which may be due to the non-linear relationship between the input parameters and the output parameters. Feng Jinping et al. [61] analyzed the parameters of the Kostiakov three-parameter model by establishing a multivariate linear forecast model. The prediction accuracy is within the allowable range, but the equation can hardly reflect the nonlinear nature of the parameters. Since then, the research results of many scholars have shown that the linear regression prediction model of soil water infiltration parameters is simple in form, convenient in calculation, and widely used. However, most of the prediction accuracy is not high and cannot reflect the true relationship between input parameters and output infiltration parameters.

\section{2 nonlinear regression prediction model for soil water infiltration parameters}

Because linear regression models often do not conform to actual infiltration conditions, relevant scholars have begun to conduct research on nonlinear regression analysis. Saxton [62] and Minasny [63] studied the functional relationship between soil physical and chemical parameters including texture, bulk density, organic matter, etc., and infiltration parameters under different soil matrix potentials. The analysis found that the nonlinear forecast model can make more accurate predictions on the measured values. In 2010, Liao Kaihua et al. [64] substituted the conventional physical and chemical parameters of soil into the nonlinear regression model and found that the nonlinear fitting curve was closer to the measured curve, and the model prediction accuracy was higher. Analysis found that the nonlinear fitting curve is closer to the measured curve, and the model prediction accuracy is higher. Since then, the research results of many scholars have shown that the non-linear regression forecast model of soil water infiltration parameters has high prediction accuracy and can truly reflect the non-linear nature of input parameters and output infiltration parameters.

\section{3 prediction model of soil water infiltration parameters based on artificial neural network}

In 1986, scientists such as Rumelhart and McClelland proposed the concept of BP (back propagation) neural network, which is a multilayer feedforward neural network trained according to the error back propagation algorithm [65]. In 2003, Wang Zhi qiang [66] established a function model of sandy soil conventional physical and chemical parameters and infiltration water holding parameters. In the modeling stage, the nonlinear regression model is better than the BP model. But in the verification stage, the effect of the BP model is better than the prediction effect of the nonlinear model, and the stability is stronger. In 2013, Yuan Lin $\mathrm{Hu}$ [67] 
established the BP model of Philip model parameters. The prediction effect of each soil water infiltration parameter is better than the regression models. Since then, the research results of many scholars have shown that the artificial neural network prediction model of soil water infiltration parameters has the highest prediction accuracy. But the disadvantage is that the calculation is too complicated, and often does not achieve the global optimal effect, which is not conducive to practical application.

\section{Conclusions and prospects}

As an important link in the transformation of the "five waters" and a key factor affecting the growth and development of crops in farmland, the research on soil infiltration has achieved many results. However, due to the particularity and complexity of soil water movement characteristics, there are still many deficiencies in the study of soil water infiltration, which needs to be further improved. Combining the existing research results at home and abroad, the current problems in soil infiltration research and future research directions are mainly reflected in the following aspects.

\section{1 the mechanism of enhancing soil chemistry effect on infiltration characteristics.}

The current research on soil moisture infiltration is mainly about the influence of the basic physical and chemical properties of soil on the infiltration process and infiltration capacity, but there are few studies on the influence mechanism of soil chemistry [44]. Due to the complexity of the distribution and movement of soil water, research on the chemical properties of the earth's soil water (such as the composition and migration of elements) has been slow. Therefore, research on the influence mechanism of soil water sampling methods and soil chemistry in the infiltration process needs to be strengthened [3].

\section{2 the mechanism of enhancing soil water infiltration on ecological restoration.}

With the progress of society and the growth of population, the water ecological environment is further degraded [5]. However, the current research on soil water infiltration is mostly focused on the impact on crop growth and the efficient use of irrigation water, while the research on the impact of infiltration on pollution control and ecological restoration is scarce. Therefore, in the future environment where pollution and ecological problems become more acute, from the perspective of soil water, it is an effective way to strengthen the study of the mechanism of soil water infiltration on ecological restoration and pollution control [3].

\section{3 strengthen the study of soil water infiltration process under the coupling of multiple factors.}

Most of the traditional soil water infiltration studies consider the influence of three factors (such as temperature, water quality, soil bulk density, etc.) on the infiltration process, and most of them are single-point experimental observations. The research on the influence mechanism still needs to be improved. However, soil infiltration in the actual ecological environment is a very complicated process. Any changes in environmental factors and soil factors may affect the dynamic movement of soil water. Future research on the infiltration process should strengthen the connection with the SPAC (Soil-Plant-Atmosphere Continuum) system, and fully consider the mutual feedback of all relevant material information during the infiltration process and the dynamic impact of the environment. This can make the research results closer to the real soil infiltration environment, and can provide a more scientific and reasonable parameter basis for agricultural production practices.

\section{4 strengthen long-term monitoring of soil water movement in large scale watershed areas}

The current human agricultural planting scale is getting larger and larger. However, current soil water infiltration research experiments are mainly local single-point experiments, with small spatial scales and short time spans, which are not representative. Therefore, future research on soil moisture infiltration should be based on $3 \mathrm{~S}$ technology and big data statistical analysis technology to build a large-scale long-term dynamic monitoring platform for soil moisture infiltration. At the macro level, strengthen long-term research on the process and nature of soil water movement in a wide range of watersheds.

\section{5 strengthen the prediction model of soil water infiltration.}

Due to various limiting factors, it is very difficult to obtain scientific and accurate soil water infiltration parameters through field tests. Therefore, in the future development of more refined and data-based agriculture, the establishment of higher prediction accuracy infiltration parameter prediction models is the future research and development direction. This is of great significance to water and soil conservation and the development of more advanced and efficient irrigation techniques and equipment. 


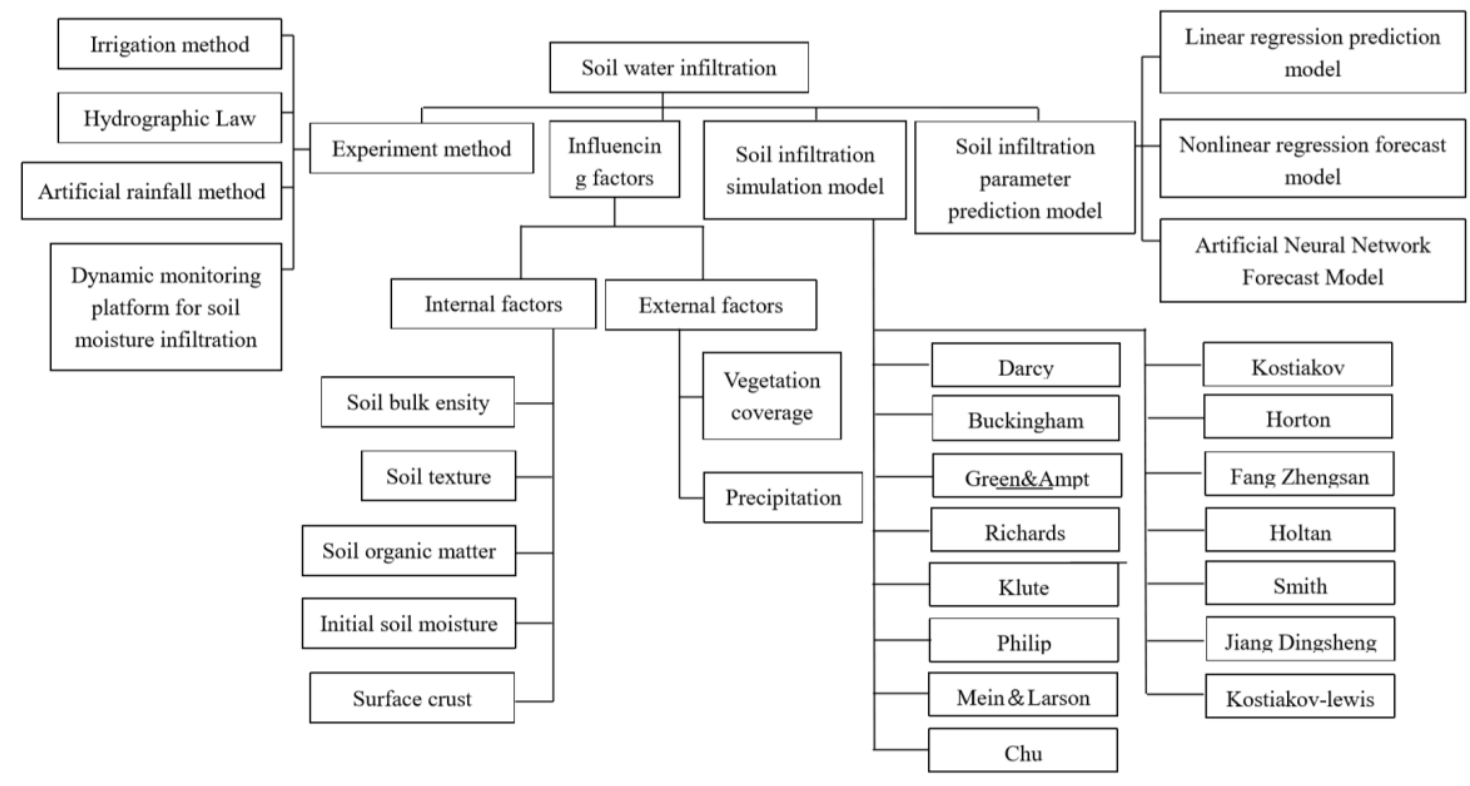

Figure 1 Distribution map of main research progress on soil water infiltration

\section{Acknowledgments}

Authors thanks to the support of Sichuan Provincial Department of Science and Technology Project

(2019YJ0430) and College Student Innovation Training Program (202010626139)

\section{References}

1. Lei Z D, Hu H P,Yang S X. (1999) A Review of Soil Water Research[J].Advances in Water Science, (3):311-318.

2. Štekauerová V, Nagy V, Kotorová D.(2006) Soil water regime of agricultural field and forest ecosystems[J].Biologia, 61(19):S300-S304.

3. Xiao D A, Wang S J. (2009) Comments on the progress and direction in soil water research [J].Ecology and Environmental Sciences, 18(3):1182-1188.

4. Liu L F, Xu X Y, Wang H X, et al.(2009) Advances in soil water resource assessment[J].Journal of Beijing Normal University(Natural Science), 45(5):621-625.

5. Wilk Sampaio de Almeida, Elói Panachuki, Paulo Tarso Sanches de Oliveira, et al.(2008) Effect of soil tillage and vegetal cover on soil water infiltration[J].Soil \& Tillage Research,175.

6. Jin S W, Zhou B J, Teng Z H.(2018)Study on the characteristics of soil water infiltration in Chengde with multilayer plant landscape design in limited space[J].Bulletin of Science and Technology, 34(3):101-104.

7. Song A Y, Dong L S, Liu S R, et al. (2018) Soil infiltration characteristics and its influencing factors indifferent subalpine meadow communities[J].Research of Soil and Water Conservation, 25(3):41-45.

8. Bondeau A, Smith p, Lucht W, et al.(2005) Contemporary 'green' water flows: Simulations with a dynamic globalvegetation and water balance model[J].Physics and chemistry of the earth,30(6/7):334-338.

9. Dai Z H, Jiang T M, Liu H B. Research progress in soil water infiltration[J]. Guizhou Agricultural Sciences, 2008(05):77-80.

10. Lv Z Y,Liu S S, Qin T L, et al.(2019) Comment on the progress and major direction of soil infiltration research $[\mathrm{J}]$.China Rural Water and Hydropower, (7):1-5.

11. Whitaker S. (1986) Flow in porous media I: A theoretical derivation of Darcy's law[J].Transport in Porous Media, 1(1).

12. Yang J L, Zhu L L, Zhu J C. (1982) Research on soil water holding capacity in Shanghai area [J]. Acta Soil Science, 19 (4): 331-341.

13. Yang X K, Wang Y, Zhao L P, et al.(2014) Research progress on hydrodynamic parameters and its affecting factors[J]. Chinese Agricultural Science Bulletin, 30(3):38-43.

14. Richards L A. (1931) Capillary conduction of liquids through porous mediums $[\mathrm{J}]$.Physics, 1931(1) : 318-333.

15. J. R. Philip,D. A. De Vries.(1957) Moisture movement in porous materials under temperature gradients[J].Eos, Transactions American Geophysical Union, 38(2):222-232.

16. Yu L Y. (2016) Simulation of water and heat transfer SPAC system for summer maize under conditions of different water supply[D]. Northwest A\&F University.

17. Jiang D S, Huang G J, (1986) Study on soil infiltration rate of loess plateau[J].Acta Pedologica Sinica, 1986(4): 299-305.

18. Sun S F. (1988) Research on the law of soil infiltration under rainfall[J].Acta Pedologica Sinica, 25(2): 119-124.

19. Lei Z D, Yang S X, Xie S C, et al. (1988) Soil hydrodynamics, Tsinghua University Press, Beijing. 
20. Zhu L J, Zhang G H, Ren Z P. (2012) Comparing four methods for soil infiltration measurement[J].Bulletin of Soil and Water Conservation, 32(6): 163-167.

21. Zhang J, Lei T W, Qu L Q, et al.(2017) Method to measure soil matrix infiltration in forest soil[J].Journal of Hydrology, 552:241-248.

22. Ren Z P, Zhang G H, Wang P, et al.(2012) Effects of double-ring diameter on soil infiltration rate[J].Journal of Soil and Water Conservation, 26(4):94-97,103.

23. Mo B, Chen X Y, Liu T, et al.(2016) Study on soil infiltration and its determination methods in purple hilly region[J].Journal of Soil and Water Conservation, 30(2): 116-121.

24. Zhou L Y, Chen Z X, Li W M. (2003) Calibration on measurement of soil water content using time domain reflectrometry (TDR) [J].Acta Pedologica Sinica, 40(1):59-64.

25. Schwarzel K. Punzel J. (2007)Hood infiltrometer: A new type of lension infiltrometer[J]. soil science society of America JOurnal, 71(5): 1438.

26. Li Y X, Lv G ,Wang D H, et al. (2019) Analyzing the saturated hydraulic conductivity of surface soil in a dump by three measuring methods[J].Science of Soil and Water Conservation, 17(5):65-74.

27. Zhai Z N, Wang K Q, Su B. (2016) Application of guelph permeameter in determining the soil permeability of the Songhuaba Water Source Area in Kunming city[J].Journal of Sichuan Agricultural University,34(2):215-220,226.

28. Zhu A N, Zhang J B, Chen D L. (2000) Field determination of soil saturated hydraulic conductivity [J].Soils, 32(4):215-218.

29. [29]Dai Z H, Jiang T M, Liu H B.(2008) Research progress in soil water infiltration $[\mathrm{J}]$. Guizhou Agricultural Sciences,2008(05):77-80.

30. Wang J, Jia J W, Zhang M B, et al. (2017) Hydrological analysis calculation and sponge city $[\mathrm{J}]$. China Flood \& Drought Management, 27(3): 74-78.

31. Huang Z, Tian F P, Wu G L, et al.(2017) Legume grasslands promote precipitation infiltration better than gramineous grasslands in arid regions[J].Land Degradation \& Development, 28(1):309-316.

32. Fang B, Lakshmi V . (2014) Soil moisture at watershod scale : Remote sensing techniques $[\mathrm{J}]$. Journal of Hydrology, 516(6): $258-272$

33. Zheng J Y, Shao M A, Zhang X C. (2004) Spatial variation of surface soil's bulk density and saturated hydraulic conductivity on slope in loess region[J].Journal of Soil and Water Conservation, 18(3):53-56.

34. Lv G, Wu X Y. (2008) Review on influential factors of soil infiltration characteristics[J].Chinese Agricultural Science Bulletin,2008(07):494-499.

35. Pan Y, Lv D Q. (2009) Effects of Soil Bulk Density on Characteristics of Soil Infiltration[J].Journal of Irrigation and Drainage, 28(02):59-61, 77.
36. Zeng J, Fei L J, Pei Q B. (2017) Influence of soil bulk density on soil water infiltration characteristics in water vertical movement for red loams[J].Journal of Drainage and Irrigation Machinery Engineering, 35(12):1081-1087.

37. Li Z, Wu P T, Feng H, et al. (2009) Simulated experiment on effect of soil bulk density on soil infiltration capacity[J].Transactions of the Chinese Society of Agricultural Engineering, 25(06):40-45.

38. Xie W Y, Fan G S. (2004) Influence of soil structure on infiltration characteristics in field soils[J].Journal of Taiyuan University of Technology,2004(05):537-540.

39. Liu X Z ,Kang S Z. (1999) Some Developments and Review of Rainfall-Infiltration-Runoff Yield Research[J].Bulletin of Soil and Water Conservation, 1999(02):60-65.

40. Wu Y, Chen J. (2016) Study on determination of soil organic matter by potassium dichromate volumetric method-heating method[J].China High-Tech Enterprises,2016(26):11-12.

41. Shan X Z, Wei Y Q, Yan H J, et al. (1998) Effects of soil organic matter content on soil hydrodynamic parameters[J]. Acta Pedologica Sinica,1998(01):1-9.

42. Zheng J, Li X Y, Ma J, et al. (2020)Effect of biogas slurry combined with straw biochar on soil organic matter and total nitrogen content[J].Journal of Agro-Environment Science, 39(05):1111-1121.

43. Zhao X N, Wu F Q. (2004) Developments and reviews of soil infiltration research[J].Journal of Northwest Forestry University, 19(1): 42-45.

44. Guan J W. (1996) Principles of Soil and Water Conservation, China Forestry Publishing House, Beijing.

45. Jia Z J, Wang G P, Li J Y, et al. Research on the influence of soil moisture content on land flow on slope farming $[\mathrm{J}]$. Shanxi Soil and Water Conservation Science and Technology, 1990, 22(4): 25-27.

46. Zhang Z G, Zhao H R.(1999)Rainfall infiltration experiment in different land types in Huangqiu area[J].Soil and Water Conservation Science and Technology in Shanxi, (02):7-9.

47. Li F W, Fei L J.(2003) Experimental study on characteristic and influential factors of film hole bilateral interference infiltration[J].Journal of Soil and Water Conservation,2003(04):105-109.

48. Jia Z J, Wang X P. (2002) Study on influence of soil moisture of summer slack farming slopped lands due to crusted loess surface[J].Soil and Water Conservation in China, 9:18-19.

49. Yang F, Yao W Y ,Dai W H, et al.(2013) Progress of the water erosion study on the vegetationgal slope[J]. Yellow River, 35(1):72-74.

50. Zhang Z Q, Wang L X, Yu X X, et al.(2001) Impacts of forest vegetation on runoff generation mechanisms: a review[J].Journal of Natural Resources,2001(01):79-84.

51. Wang G X, Shen Y P ,Wang J D.(2003) Study on the influence of vegetation changeon soil moisture cycle in alpine meadow[J].Journal of Glaciology 
and Geocryology,2003(06):653-659.

52. Wang B T. (2015) The contribution of soil-root interstice to rainfall infiltration in soil of well vegetated slope[D]. Kunming University of Science and Technology.

53. Bai S Y. (2015) Study on progress of soil moisture changing in loess soil column[D]. Northwest A\&F University.

54. Zhao X N, Wu F Q, Wang W Z. (2004) Research on soil infiltration law of slope farmland in gully area of loess plateau[J].Journal of Arid Land Resources and Environment, 18(4):109-112.

55. Shi S X. (1992) A testing study of factors affecting infiltration rate under artificial rainfall with high intensity $[\mathrm{J}]$. Bulletin of Soil and Water Conservation, 12(2):49-54.

56. Yang Y H ,Zhao S W, Lei T W,et al. (2006) Tillage on soil infiltration under simulated rainfall conditions[J]. Acta Ecologica Sinica, 26(5):1624-1630.

57. Helalia A M, Letey J, Graham, R C. (1988) Crust formation and clay migration effect son infiltration rate[J].Soil SciSocAm, 52:251-255.

58. Guo H ,Fan G S. (2015) Kostiakov parameter nonlinear prediction model for thawing soil water infiltration[J].Water

Saving Irrigation, 2015(11):1-4+8.

59. Gupta S C,Larson W E.(1979) Estimating soil water retention characteristics from particle size distribution,organic matter percent and bulk density [J].Water Resources Research, 15:1633-1635.

60. Minasny B, McBratney A B, Bristow K L. (1999) Comparison of different approaches to the development of pedotransfer functions forwater-retention curves[J]. Geoderma, 93:225-253

61. Feng J P ,Fan G S. (2014) Linear Transfer Function Research of Soil Water Infiltration Parameter[J].China Rural Water and Hydropower,2014(09):8-11+22.

62. Saxton K E,RawlsW J,Romberger J S, (1986) Papendick R I. Estimating generalized soil-water characteristics from texture[J].Soil Science Society of America Journal, 50:1031-1036.

63. Minasny B, McBratney A B, Bristow K L. (1999) Comparison of different approaches to the development of pedotransfer functions for water-retention curves[J].Geoderma, 93:225-253

64. Liao K H, Xu S H, Cheng G F, et al.(2010) Spatial variability analysis of soil water retention capability at basin scale based on different ptfs[J].Acta Pedologica Sinica,2010,47(01):33-41.

65. He F W, Wang W H, You M H, et al. (2018) The Research on Intelligent Home Control Based on Neural Network. J. Electronics Quality , 2018(12):50-53.

66. Wang Z Q. (2003) Estimation of soil hydraulic characteristic properties of Keerqin sandy land[D].Inner Mongolia Agricultural University.

67. Yuan L H. (2013) Research and application of philip infiltration model parameters prediction[D].Taiyuan University of Technology. 